\title{
A Comparison of Brand Loyalty Between On-the-Go and Take-Home Consumption Purchases: An Abstract
}

\author{
Giang Trinh
}

\begin{abstract}
This paper compares consumer behavioral brand loyalty in purchasing for on-the-go and for take-home consumption. The study uses two consumer packaged goods datasets from the UK. The first dataset contains actual consumer repeat purchasing of soft-drink brands for on-the-go consumption. The second dataset contains actual consumer repeat purchasing of the same brands for take-home consumption. Using polarization index as a behavioral loyalty measure, estimated from the Beta Binomial - Negative Binomial Distribution, the study finds that consumer loyalty to brands is markedly higher in purchasing for on the go consumption than for take home consumption.
\end{abstract}

References Available Upon Request

G. Trinh $(\bowtie)$

University of South Australia, Adelaide, Australia

e-mail: giang.trinh@marketingscience.info 